\title{
Characterization and treatment of colored textile wastewaters from the typical Tunisian hat Chechia dyeing using newly isolated Aspergillus niger
}

\author{
Hajer Barouni ${ }^{1, *}$, Haifa Chahed ${ }^{2}$, Manel Ziadi ${ }^{1}$, Kaouther Zaafouri ${ }^{1}$, Mohamed Nejib Marzouki ${ }^{2}$ and \\ Moktar Hamdi ${ }^{1}$ \\ ${ }^{1}$ Laboratory of Ecology and Microbial Technology (LETMi). The National Institute of Applied Science and \\ Technology INSAT. Carthage University. 2 Boulevard de la Terre, BP 676, 1080 Tunis, Tunisia. \\ ${ }^{2}$ Laboratory of Protein Engineering and Bioactive Molecules (LIP-MB). The National Institute of Applied \\ Sciences and Technology INSAT. Carthage University. 2 Boulevard de la Terre, BP 676, 1080 Tunis, Tunisia.
}

\begin{abstract}
This study aimed to characterize and investigate, for the first time, the treatment of real colored wastewaters from the artisanal dyeing of the typical Tunisian hat Chechia, using a newly isolated fungal strain. This textile effluent was a mixture called Mix of colored wastewaters from the three main types of Chechia. The major pollutant of the Mix was the toxic Azo dye Amaranth Acid or Acid Red 27. The fungal strain that made the cleanup was discovered in a Chechia dyeing wastewater's container and identified by ITS rDNA gene sequencing. This isolated Aspergillus niger showed interesting performances on the demonstration of Chechia wastewater's biodegradation in batch cultures. In order to understand the effect of agitation, Mix dilution and inoculum size on decolourisation and pollution removal, a full factorial experimental design $2^{3}$ was set up. At the optimal conditions which were 20\% inoculum size, 25\% Chechia Mix dilution and an agitation of $100 \mathrm{rpm}$, Aspergillus niger was able to remove color as high as $70.18 \pm 2.84 \%$ at an initial dye concentration of $1346.6 \pm 0.01 \mathrm{mg} / \mathrm{L}$, and to reduce COD to $74.17 \pm 14.52 \%$ at an initial COD of $4157 \pm 422 \mathrm{mg} / \mathrm{L}$. FT-IR spectra analysis confirmed the decolourisation by biodegradation and transformation of the dyes. The treatment by the isolated Aspergillus niger could be successfully applied as a sustainable method to solve one of handicraft dyeing plants environmental management issues.
\end{abstract}

Keywords: Chechia artisanal textile wastewater; Red Azo dyes; decolourisation; Aspergillus niger; full factorial design.

\section{Introduction}

The wastewater generated from textile and tanning industries contains the highest amount of undesirable dyes and pigments. Field investigations on the Tunisian traditional red wool hat called Chechia artisanal dyeing plant revealed that the major chemical dye used for all types of Chechia was an anionic azoic dye, the Acid Red 27. This dye deserved a serious attention because of its sanitary risks. Suspected carcinogen, a risk of allergy was also reported particularly on salicylates sensitive subjects. With an increasing production of more than $81000 \mathrm{~kg} /$ year of Chechias, Tunisia is facing a huge environmental issue caused by more than $21.610^{6}$ $\mathrm{L} /$ year of red wastewaters from a unique artisanal dyeing plant (personal data). The depollution of this colored effluent could contribute to achieving the global environmental management of this focal handicraft dyeing plant. This is a requirement of the Tunisian Eco Label for Chechia that is an artisanal

*Corresponding author: Hajer Barouni

Email address: barouni_hajer@yahoo.fr

DOI: http://dx.doi.org/10.13171/mjc61/01609141224/barouni product with a high patrimonial value. A particularly common aspect of textile effluents is the high COD. In order to overcome this problem, varied methods were explored to treat textile wastewater. Coagulation flocculation, membrane filtration, and chemical processes have all been widely used in the remediation of textile wastewaters ${ }^{1}$. Several advanced oxidation processes such as photocatalysis, Fenton and photo-Fenton were proposed ${ }^{2}$. However, most of the literature studies on destructive treatment methods for the cleanup of textile wastewaters reported decolourisation efficiencies, but not COD removal or mineralization. In case of toxic and biodegradable textile wastewaters, biological treatment is an alternative to these physical methods; it has a special interest and is in a constant development which contributes to the realization of high reactions yields with a sustainable treatment ${ }^{3}$. Biological treatment is a common process widely applied in the treatment of wastewater polluted with

Received July $2^{\text {nd }}, 2016$

Accepted August 28 ${ }^{\text {th }}, 2016$

Published September 14 ${ }^{\text {th }}, 2016$ 
dyes. It offers significant advantages in terms of cost and level of toxicity of the final products.

Bacteria are frequently solicited for the bioremediation of textile discharges because of their rapid growth and adaptability even in extreme conditions of salinity, $\mathrm{pH}$ and temperature, in addition to the expression of a dye specific enzyme system ${ }^{4}$. Many species have been sought for the bleach and the mineralization of various dyes ${ }^{5}$. However, most of the dyes from all chemically distinct groups are also prone to fungal oxidation ${ }^{6}$. Their large structural differences constitute a great challenge for the varying catalyzing properties of the fungal isolates. Biodegradation of azo and phalocyanin dyes was analyzed by using the common polypore mushroom Trametes versicolor and the white rot fungus Bjerkandea adusta 6 . Literature reported the degradation of azo, anthraquinone, heterocyclic and polymeric dyes by Phanerochete chrysosporium being the most studied fungi facing the degradation of xenobiotics such as azo dyes and synthetic one ${ }^{7}$. The Members of Zygomycetes such as the mucoraceous and arbuscular mycorhizal fungi, but also aquatic and anaerobic fungi can be applied for bioremediation. In the cleanup of industrial effluents from undesirable chemicals, the yeasts such Candida tropicalis, Saccharomyces cerevisiae, Saccharomyces carlbergensis and Candida utilis are other significant candidates. Furthermore, consortia of Fungi and Bacteria are used in composing a waste disposal practice ${ }^{7}$. Depending on the fungus species, several mechanisms could be involved in decolourisation: dyes can be removed by fungi via enzymatic mineralization using Lignin peroxidase (LiP), Manganese peroxidase (MnP), and Laccases (Lacc) ${ }^{4}$, by bioadsorption ${ }^{8}$ and also by biodegradation ${ }^{7}$. Oxidation of synthetic dyes by White Rot Fungi implies the expression of non-specific extracellular ligninolytic enzymes. The capability of laccase to act on chromophore compounds such as azo, triarylmethane, anthraquinonic and indigoid dyes leads to the suggestion that they can be applied in industrial decolourisation processes ${ }^{9}$. The enzyme laccase produced by Pyricularia oryzae oxidizes Phenolic azo dyes. Reactive dyes typically contain azo based chromophores attached to different types of reactive groups that interact with the active sites such as chitin, chitosan acidic polysaccharides, lipids, amino acid and other cellular components on the surface of the micro-organisms ${ }^{10}$. Several degradation mechanisms for non-phenolic and phenolic azo dyes are proposed in literature. Azo dyes can be degraded through a highly non-specific free radical mechanism, forming phenolic type compounds, without direct cleavage of the azo bond and avoiding the formation of toxic aromatic amines, which might be friendly for the environment ${ }^{11}$. In biodegradation, maximum decolourisation rate is generally reached during the exponential growth phase of the micro-organism. Also, additional substrates such as glucose could enhance the decolourisation ${ }^{12}$. Literature also reported that various physicochemical conditions such as the type and concentration of dyes, additional carbon, nitrogen source, temperature and $\mathrm{pH}$ largely influence the fungal biodegradation. Other fungal species like Aspergillus niger are able to decolourise and /or absorb various dyes ${ }^{7}$. Jaidev and Narasimha (2010) showed that Rose Bengal dye at 100 ppm was effectively decolourised by $A$. niger within a 24 hour incubation period ${ }^{13}$. Aspergillus niger, isolated from the soil around textile industries, could tolerate high concentrations of dyes (up to $1000 \mathrm{mg} / \mathrm{L}$ ) and displayed a high decolourising activity against various reactive dyes including azo dyes as reported by SA Omar ${ }^{14}$.

This research could help respond to the increasing sustainability requirements of the artisanal processes as well as to the reduction of the ecological footprint of products. The objectives of the present study are threefold: $i$ ) reporting for the first time the characterization of the Chechia colored effluent, ii) demonstrating its biodegradation in batch cultures using an isolated Aspergillus niger and iii) determining the optimal conditions of depollution and decolourisation from its major pollutants, the acid azo dyes. Coupling handicraft with environment should increase the international influence of Chechia, placing this Tunisian symbol in the "green" rank of the cleanly processed products.

\section{Materials and Methods}

\section{Effluent sampling}

The colored textile wastewaters used in this study came from an artisanal dyeing plant of Chechia located in the old City of Tunis (capital of Tunisia). Samples have been collected from the Chechia dyeing marmites when the dyeing process was complete and before the colored wastewaters have been discharged into the public sewage system. Access to dye marmites was direct. Three types of colored wastewaters derived from three used types of Chechia: bright red wastewaters from the Chechia Tounsi dye, dark red wastewaters from the Chechia Ben Ghazi dye and black wastewaters derived from the black Chechia Trabelsi dye. A mixture of the three colored effluents at equal proportions called Mix was used as substrate for all the experiments.

\section{Isolation and identification of the fungal strain} Isolation and characterization of the fungus

The fungal strain used in the present work was isolated from an abandoned effluent sample; as it already seemed to visually present interesting dye removal abilities. The isolation of the strain was carried out by successive subcultures on a specific medium composed of: $250 \mathrm{~mL}$ of diluted Mix (25\%) supplemented with $7.5 \mathrm{~g}$ Agar. The incubation was carried out at $30^{\circ} \mathrm{C}$ during 5 days. For phenotypic and molecular characterization, the strain was grown 
in the classical media Potatoes Dextrose Agar (PDA) and Potatoes Dextrose Broth (PDB) (REACTIFS RAL) and incubated at $30^{\circ} \mathrm{C}$ for 3 days. Microscopic observations were done at 10,40 and 100 magnifications using an optical microscope (LIIOOA) equipped with a camera.

\section{Total genomic DNA extraction}

The total genomic DNA of the fungus was prepared from mycelium. After 3 days of preculture on PDB medium, the fungal mycelium was ground in liquid nitrogen until obtaining a viscous liquid suspension. Three hundred milligrams of the ground material were weighed in an Eppendorf sterile tube to which were added $400 \mu \mathrm{L}$ of genomic DNA extraction buffer. The sample was gently homogenized and added with $250 \mu \mathrm{L}$ of $3 \mathrm{M}$ ammonium acetate ( $\mathrm{pH} 4.8$ ). After $30 \mathrm{~min}$ of incubation on ice, the sample was centrifuged for 15 min at $13000 \mathrm{rpm}$ at $4^{\circ} \mathrm{C}$. A carefully recovered aqueous phase was added to $1 \mathrm{~V}$ of phenol saturated in extraction buffer ( $\mathrm{pH}$ 8). The whole was thoroughly mixed and centrifuged for $5 \mathrm{~min}$ at 10 $000 \mathrm{rpm}$. The upper aqueous phase was recovered for re-extraction with $1 \mathrm{~V}$ of chloroform. After homogenization and centrifugation for $5 \mathrm{~min}$ at 10 $000 \mathrm{rpm}, 2 \mathrm{~V}$ of absolute ethanol and $1 / 10 \mathrm{~V}$ of $3 \mathrm{M}$ sodium acetate ( $\mathrm{pH} 4.8$ ) were added to the aqueous phase. The whole was incubated for 2 hours at $80^{\circ} \mathrm{C}$, then centrifuged for $15 \mathrm{~min}$ at $12000 \mathrm{rpm}$ at $4^{\circ} \mathrm{C}$. The pellet was then washed with $70 \%$ ethanol, centrifuged $2 \mathrm{~min}$ at $10000 \mathrm{rpm}$, dried and finally re-suspended in $30 \mu \mathrm{L}$ extraction buffer. The genomic DNA obtained was analyzed by electrophoresis agarose gel $0.8 \%$ in the presence of the $1 \mathrm{~Kb}$ Ladder molecular weight markers. The genomic DNA is then stored at $-20^{\circ} \mathrm{C}$.

Polymerase Chain Reaction (PCR) amplification, DNA sequencing and phylogenetic analysis

The fungal genomic DNA was subjected to amplification by PCR using specific primers ITS 1:5'-TCCTCCGCTTATTGATATGC-3' and ITS4:5'-GAAGTAAAAGTCGTAACAAGG-3'.

PCR was performed using a $50 \mu \mathrm{L}$ reaction mixture containing the following (per reaction) : $100 \mathrm{ng}$ of genomic DNA; 1X DreamTaq reaction buffer (Thermo) ; $10 \mathrm{mM}$ of dNTP mix ; $20 \mu \mathrm{M}$ of each primer; $1.25 \mathrm{U}$ DreamTaq DNA polymerase (Thermo). Amplifications were performed in a BIORAD Thermocycler and the different PCR steps were as follows: an initial denaturation step at $94^{\circ} \mathrm{C}$ for $5 \mathrm{~min}, 30$ cycles of: denaturation at $94^{\circ} \mathrm{C}$ for 1 min, annealing at $49^{\circ} \mathrm{C}$ for $1 \mathrm{~min}$, and extension at $72^{\circ} \mathrm{C}$ for $1 \mathrm{~min} 30 \mathrm{~s}$, followed by a $10 \mathrm{~min}$ final extension step at $72^{\circ} \mathrm{C}$. Five microliters of the mixture were finally analyzed by electrophoresis on $1 \%$ agarose gel and visualized by Ethidium Bromide. The nucleotide sequence of the ITS region of the cleaner fungus genomic DNA was amplified by PCR. The amplified PCR products were then sequenced, using the BigDye ${ }^{\circledR}$ Terminator v3.1 Cycle Sequencing kit. The obtained sequence was then analyzed using the Blast alignment program. Results were represented in a phylogenic tree. The Neighbor-Joining method ${ }^{15}$ was used. The evolutionary distances were computed using the Jukes-Cantor method and were in the units of the number of base substitutions per site. The analysis involved 11 nucleotide sequences. Evolutionary analyses were conducted in MEGA6 ${ }^{16}$.

\section{Analytical methods}

Determination of $\mathrm{pH}$, conductivity, TS, TVS, TSS, $\mathrm{COD}, \mathrm{BOD}_{5}$ and Color

The determination of $\mathrm{pH}$, conductivity, Total Solids (TS), Total Volatile Solids (TVS), Total Suspend solid (TSS) and Chemical Oxygen Demand (COD) of the effluent were carried out according to standard methods ${ }^{17} \cdot \mathrm{pH}$ values were measured using the $\mathrm{pH}$ meter (METTLER TOLEDO Education Line). The conductivity was measured using a conductivity meter (TOLEDO type MC 226). TS were determined by evaporation of a volume $\mathrm{V}$ (10 $\mathrm{ml}$ ) of the test sample in a crucible by incubation in a drying oven (JOUAN S') at $105{ }^{\circ} \mathrm{C}$ for 24 hours. It was then calcined in the muffle furnace (PROTHERM FURNACES) model at $550{ }^{\circ} \mathrm{C}$ for 2 hours to determinate the TVS. Samples were centrifuged $3000 \mathrm{rpm} / \mathrm{min}$ for $20 \mathrm{~min}$; the COD was measured using a PALINTEST 5000 photometer on the supernatant after the end of the centrifugation; the pellet was placed in a crucible and in an oven at $105{ }^{\circ} \mathrm{C}$ for 24 hours to determine TSS. The determination of the Biological Oxygen Demand $\left(\mathrm{BOD}_{5}\right)$ was made by the electrochemical method according NF 1899 (1998). The biological oxygen demand was the amount of oxygen in mg of oxygen that is consumed by the biodegradable material in one liter of sample under the conditions of the test, after five days incubation at $20{ }^{\circ} \mathrm{C}$ in the dark. For Color determination, the sample was centrifuged 20 min at $3000 \mathrm{rpm}$ and the optical density (OD) of the supernatant was measured at a $K_{\max }$ of $525 \mathrm{~nm}$ with an UV-Visible (SECOMAN XS2 model) calibrated with distilled water. The decolourisation yield was expressed in percentage of color removal (\%).

Determination of Nitrogen, Phosphorus, Nitrates, Chlorides, Fluorides, Potassium and Heavy metals

Ammonia and organic Nitrogen concentration expressed in $\mathrm{mg} \mathrm{N} / \mathrm{L}$ were determined following the method after mineralization in selenium according to NF 25663/ ISO 5663 (1994). This method permitted to determinate nitrogen in the negative trivalent state. The sample was mineralized to $350{ }^{\circ} \mathrm{C}$ in an acid medium in the presence of Selenium as catalyst and Potassium sulfate (elevation of boiling point). Phosphorus was determined following the spectrometric dosing method using Aluminium molybdate, according to ISO 6878 (2004). The sample was mineralized using persulfate at $120^{\circ} \mathrm{C}$, 
transforming many organophosphates into orthophosphates. The concentration of orthophosphate in the sample was determined after absorbance measurement at $880 \mathrm{~nm}$. Determination of Nitrates, Chlorides and Fluorides in contaminated waters were made by chromatography in liquid phase ion according to NF ISO 10304 (1995). Separating anions by liquid chromatography column involved the use of a low-capacity ion exchange as stationary phase and an aqueous solution of a monoacid and low diacid (solution of sodium hydrogencarbonate and sodium carbonate) as mobile phase. The ion detection was made by conductimetry. Potassium and Heavy metals : Aluminium (Al), Chromium (Cr), Manganese (Mn), Cadmium $(\mathrm{Cd})$, Lead $(\mathrm{Pb})$, Iron $(\mathrm{Fe})$, Zinc $(\mathrm{Zn})$, Cobalt $(\mathrm{Co})$, Copper $(\mathrm{Cu})$ and Nickel $(\mathrm{Ni})$ were dosed using atomic emission spectrometry with inductively coupled plasma, according to NF ISO 11885 (1998). .The concentration of the elements was expressed in $\mathrm{mg} / \mathrm{L}$ from their calibration curves taking into account the dilution factor.

Fourier Transform Infrared Spectroscopy (FT-IR) analysis

Fourier Transform Infrared Spectroscopy (FTIR) analysis was performed to determine the distribution of functional groups of Chechia Mix before and after treatment in order to illustrate the biotreatment effect. Samples were prepared by lyophilizing the Chechia Mix obtaining a powder and then analyzed by FT-IR in the spectral range $4000 \mathrm{~cm}^{-1}-500 \mathrm{~cm}^{-1}$ using JASCO, FT/IR-4100.

\section{Chechia Mix biodegradation}

The biodegradation of Chechia Mix using the fungus was preliminarily carried out in non stirred batch system, in triplicate. Erlenmeyer flasks containing $100 \mathrm{~mL}$ of sterilized diluted Chechia Mix $(25 \%)$ were inoculated with biomass at an inoculum size of $10 \%$ and placed in static conditions at $30{ }^{\circ} \mathrm{C}$ during 28 days in an incubator (ENO55 model). At the end of the treatment, samples were withdrawn from the flasks; centrifuged $20 \mathrm{~min}$ at $3000 \mathrm{rpm}$ and the supernatant was used for OD at $525 \mathrm{~nm}$ measurement and COD soluble determination. For biomass estimation expressed in TVS, $10 \mathrm{~mL}$ of the samples were dried at $105{ }^{\circ} \mathrm{C}$ for 24 hours, weighted

$$
\mathrm{Cc}=1 / 4 *\left[\sum_{i=1}^{4} \mathrm{Aj} * \mathrm{Xi}\right] \quad \mathrm{Cp}=1 / 4 *\left[\sum_{i=1}^{4} \mathrm{Aj} * \mathrm{Yi}\right]
$$

and then calcined at $550{ }^{\circ} \mathrm{C}$ for 2 hours. Color and pollution removals respectively expressed in OD525 and COD yields were studied during the experiment as well as the fungal biomass growth expressed in TVS yield.

\section{Optimization of Chechia Mix biotreatment}

The optimization of the biodegradation of Chechia Mix using the fungal strain was carried out through full factorial experimental design $2^{\mathrm{k}}$ as described by Goupy ${ }^{18}$. The full factorial design was commonly used to study the effects of (k) factors selected at the same time, each factor having a low level (-1) and a high level (+1). $2^{3}$ experiments were done. Three independent quantitative variables were selected to reach the optimal conditions for fungal biotreatment of Chechia Mix: agitation (rpm) F1, Mix effluent dilution (\%) F2 and inoculum size (\%) F3. The full factorial experimental design was set up using $250 \mathrm{~mL}$ Erlenmeyer flasks containing $100 \mathrm{~mL}$ of Chechia Mix effluent previously autoclaved: eight Erlenmeyer flasks (E1 to E8) were inoculated with different percentages of biomass and 8 Erlenmeyer flasks were not inoculated and used as control. Inoculation was done with a preculture from Petri dishes scrapped in Chechia Mix. Erlenmeyer flasks were then incubated at $30^{\circ} \mathrm{C}$ for 35 days, either in a Shaker (LABTECH model) stirred at $100 \mathrm{rpm}$ or in an incubator (ENO55 model) according to the full factorial experimental design theoretical matrix described in Table 2 matrix. At the end of the experiment, samples were withdrawn from each flask for COD determination. For color determination, samples were centrifuged and OD 525 measurement was done on the supernatant. The experiments were carried out in duplicate. The studied responses of the experimental designs were the color removal $\mathrm{Y}_{1}$ expressed in OD 525 yield $\left(\mathrm{R}_{\mathrm{OD}} \%\right)$ and the pollution removal $\mathrm{Y}_{2}$ expressed in COD yield $\left(\mathrm{R}_{\mathrm{COD}} \%\right)$. In order to evaluate the effect of the three operating factors F1, F2 and F3 on the two responses $Y_{1}$ and $Y_{2}$, the regression coefficients $\mathrm{C}_{\mathrm{c}}$ for color removal and $\mathrm{C}_{\mathrm{p}}$ for pollution removal were determined as follow:

\section{Where:}

$A j$ : means either high (+) or low (-) level in experimental assay $\mathrm{i}$;

$X_{i}$ : the color removal $\mathrm{R}_{\mathrm{OD} 525}(\%)$;

$Y_{i}$ : the pollution removal $\mathrm{R}_{\mathrm{COD}}(\%)$;

The optimal conditions showing the best yields of color and pollution removals were adopted for the subsequent experiments as FT-IR analysis of post treated Chechia Mix. 


\section{Statistical analysis and mathematic models}

All the measurements were made in triplicate. The statistical analysis of the responses obtained after running the experimental design and the calculation of the coefficients were done with NemrodW ${ }^{\circledR}$ software version 9901 (published by Didier Mathieu, Jean Nony, Roger Phan-Tan-Lw)

$$
Y=b 0+\sum_{i=1}^{k} b i \hat{i} i
$$

\section{Results and Discussion}

\section{Effluent characterization}

The characterization of the Chechia Mix was conducted for the first time in literature through physical, chemical, biological and spectral analysis. Twenty six parameters have been evaluated and compared to Tunisian Standards NT106.002 defining and Minitab ${ }^{\circledR}$ version15 software. Checking the relationship between the three operating factors and the two responses, a first-order polynomial model studying the main effects of factors was set up. The coded mathematical model for the full factorial experimental design $2^{3}$ was expressed in this equation:

\section{Where: \\ $b 0$ : squared effect term; \\ $b i$ : regression coefficients; \\ Y: predicted response value}

the limits for discharge into public sewage and other receiving environments (Table 1). This real textile wastewater seemed different from the reported domestic wastewaters generally dark brown with bland odors. Olfactive and visual observations of Chechia Mix revealed no pronounced odor and a dark red color indicating the presence of specific pollutants that were dyes in strong concentrations.

Table 1. Characteristics of Chechia Mix, a real textile effluent from an artisanal dyeing plant

\begin{tabular}{|c|c|c|c|c|c|}
\hline \multirow{2}{*}{$\begin{array}{l}\text { Parameters } \\
\text { pH } \\
\text { at } \mathrm{T}=14.8^{\circ} \mathrm{C}\end{array}$} & \multirow{2}{*}{$\begin{array}{c}\text { Units } \\
-\end{array}$} & \multirow{2}{*}{$\begin{array}{l}\begin{array}{c}\text { Chechia Mix } \\
\text { average values }\end{array} \\
\mathbf{4 . 7 8} \pm 0.18\end{array}$} & \multicolumn{3}{|c|}{$\begin{array}{l}\text { Tunisian Standard (NT106.002) } \\
\text { limits for effluent discharge on: } \\
\text { Public sewage - Earth - Public channel }\end{array}$} \\
\hline & & & \multicolumn{3}{|c|}{$6.5<\mathrm{pH}<8.6$} \\
\hline $\begin{array}{l}\text { Electric conductivity } \\
\text { at } \mathrm{T}=14.8^{\circ} \mathrm{C}\end{array}$ & $\mu \mathrm{S} / \mathrm{cm}$ & $7745 \pm 704.5$ & \multicolumn{3}{|c|}{ no data } \\
\hline Salinity & $\mathrm{g} / \mathrm{L}$ & $4.25 \pm 1.34$ & & & \\
\hline COD & $\mathrm{mgO}_{2} / \mathrm{L}$ & $4157 \pm 422$ & 1000 & 90 & 90 \\
\hline $\mathrm{BOD}_{5}$ & $\mathrm{mgO}_{2} / \mathrm{L}$ & $1920 \pm 171$ & 400 & 30 & 30 \\
\hline Nitrogen NTK & $\mathrm{mg} / \mathrm{L}$ & $9 \pm 2.22$ & 100 & 30 & 1 \\
\hline Organic Nitrogen & $\mathrm{mg} / \mathrm{L}$ & $1.85 \pm 0.20$ & & & \\
\hline Ammonia Nitrogen & $\mathrm{mg} / \mathrm{L}$ & $7.14 \pm 2.01$ & & & \\
\hline Phosphorus & $\mathrm{mg} / \mathrm{L}$ & $\mathbf{2 . 0 5} \pm 0.26$ & 10 & 0.1 & 0.05 \\
\hline Potassium & $\mathrm{mg} / \mathrm{L}$ & $\mathbf{1 1 9 . 8 5} \pm 11.32$ & 50 & 1000 & 50 \\
\hline Nitrates $\mathrm{NO}_{3}$ & $\mathrm{mg} / \mathrm{L}$ & $\mathbf{2 4 2 5} \pm 213.17$ & 90 & 90 & 50 \\
\hline Chlorides & $\mathrm{mg} / \mathrm{L}$ & $\mathbf{2 2 5} \pm 35.35$ & 700 & No exigence & 600 \\
\hline Fluorides & $\mathrm{mg} / \mathrm{L}$ & $\mathbf{2 5 0 0} \pm 267.76$ & 3 & 5 & 3 \\
\hline Heavy metals & & & & & \\
\hline Lead $\mathrm{Pb}$ & $\mathrm{mg} / \mathrm{L}$ & $<0.005$ & 1 & 0.5 & 0.1 \\
\hline Cadmium Cd & $\mathrm{mg} / \mathrm{L}$ & $<0.0005$ & 0.1 & 0.05 & 0.05 \\
\hline Iron $\mathrm{Fe}$ & $\mathrm{mg} / \mathrm{L}$ & $\mathbf{0 . 7 2 2} \pm 0.44$ & 5 & 1 & 1 \\
\hline Copper $\mathrm{Cu}$ & $\mathrm{mg} / \mathrm{L}$ & $\mathbf{1 . 9 8 6} \pm 0.79$ & 1 & 1.5 & 0.5 \\
\hline Zinc Zn & $\mathrm{mg} / \mathrm{L}$ & $\mathbf{0 . 7 3 3} \pm 0.31$ & 5 & 10 & 5 \\
\hline Manganese Mn & $\mathrm{mg} / \mathrm{L}$ & $\mathbf{0 . 1 8 5} \pm 0.15$ & 1 & 1 & 0.5 \\
\hline Cobalt Co & $\mathrm{mg} / \mathrm{L}$ & $<0.005$ & 0.5 & 0.5 & 0.1 \\
\hline Aluminium Al & $\mathrm{mg} / \mathrm{L}$ & $\mathbf{0 . 1 3 7} \pm 0.03$ & 10 & 5 & 5 \\
\hline Chromium $\mathrm{Cr}$ & $\mathrm{mg} / \mathrm{L}$ & $<0.008$ & 0.5 & 0.5 & 0.01 \\
\hline Nickel Ni & $\mathrm{mg} / \mathrm{L}$ & $<0.005$ & 2 & 2 & 0.2 \\
\hline
\end{tabular}


Chechia Mix did not comply with the Tunisian Standard in most of pollution indicators like COD, BOD, Nitrates and Color (Table 1). This pollution was mainly due to dyes which were present at a concentration of $1346.6 \pm 0.01 \mathrm{mg} / \mathrm{L}$. The major pollutant is the " 3051 Acid Amaranth 166\%" (BORUTA COLORS) or Acid Red 27 which molecular formula is $\mathrm{C}_{20} \mathrm{H}_{11} \mathrm{~N}_{2} \mathrm{Na}_{3} \mathrm{O}_{10} \mathrm{~S}_{3}$. Listed as a food additive (E123) this dye is banned from use in several developed countries. Chechia Mix presented an acidic $\mathrm{pH}$ of $4.78 \pm 0.18$ and its high electric conductivity correlated to its salinity of $4.25 \pm 1.34 \mathrm{~g} / \mathrm{L}$ explained the major inorganic nature of the effluent in which TVS represented $25 \%$ of the TS. The TSS, Nitrogen and Phosphorus contents of the effluent were complying with the Tunisian Standard limits for effluent discharge in public sewage (Table 1). Chechia effluents could contain high levels of organic compounds which can be dangerous to environmental life, as depletion of dissolved oxygen could have an adverse effect on the marine ecological system and the whole ecosystem ${ }^{1}$. Chechia Mix COD and $\mathrm{BOD}_{5}$ were respectively
$4157 \pm 422 \mathrm{mg} \mathrm{O}_{2} / \mathrm{L}$ and $1920 \pm 171 \mathrm{mg} \mathrm{O}_{2} / \mathrm{L}$. Thus, the Chechia Mix was qualified as highly polluted compared to olive mill wastewater characteristics with COD of $95 \mathrm{~g} \mathrm{O}_{2} / \mathrm{L}$, total solids of $84.2 \mathrm{~g} / \mathrm{L}$ and total suspended solids of $14.5 \mathrm{~g} / \mathrm{L}^{19}$ or also with regard to other real textile wastewaters ${ }^{20,21}$ with COD of $1000 \mathrm{mg} \mathrm{O}_{2} / \mathrm{L}$ and $2870.6 \mathrm{mg} \mathrm{O}_{2} / \mathrm{L}, \mathrm{BOD}_{5}$ of $30 \mathrm{mg} \mathrm{O} / 2$ and $1295.3 \mathrm{mg} \mathrm{O} / 2 / \mathrm{L}$, TS of $5.810 \mathrm{~g} / \mathrm{L}$ and $10.8 \mathrm{~g} / \mathrm{L}$, and also TSS of $0.115 \mathrm{~g} / \mathrm{L}$ and $0.08 \mathrm{~g} / \mathrm{L}$. Chlorides and all the heavy metals except Copper were the only parameters that complied with the Tunisian Standard NT106.002 limits. Traces elements like Iron, Zinc and Copper detected in the wastewater could be related to the metallurgic composition of the artisanal dyeing bath which is an alloy of these metals. Chechia dyeing is an artisanal operation subjected to frequent changes as a result of its artisanal side. This is the main reason for the variable volume and the wide variety of chemical pollutants present in this wastewater. With a $\mathrm{COD} / \mathrm{BOD}_{5}$ ratio of 2.16 , Chechia effluent was not considered easily biodegradable but amenable to biological treatment with selected micro-organisms.
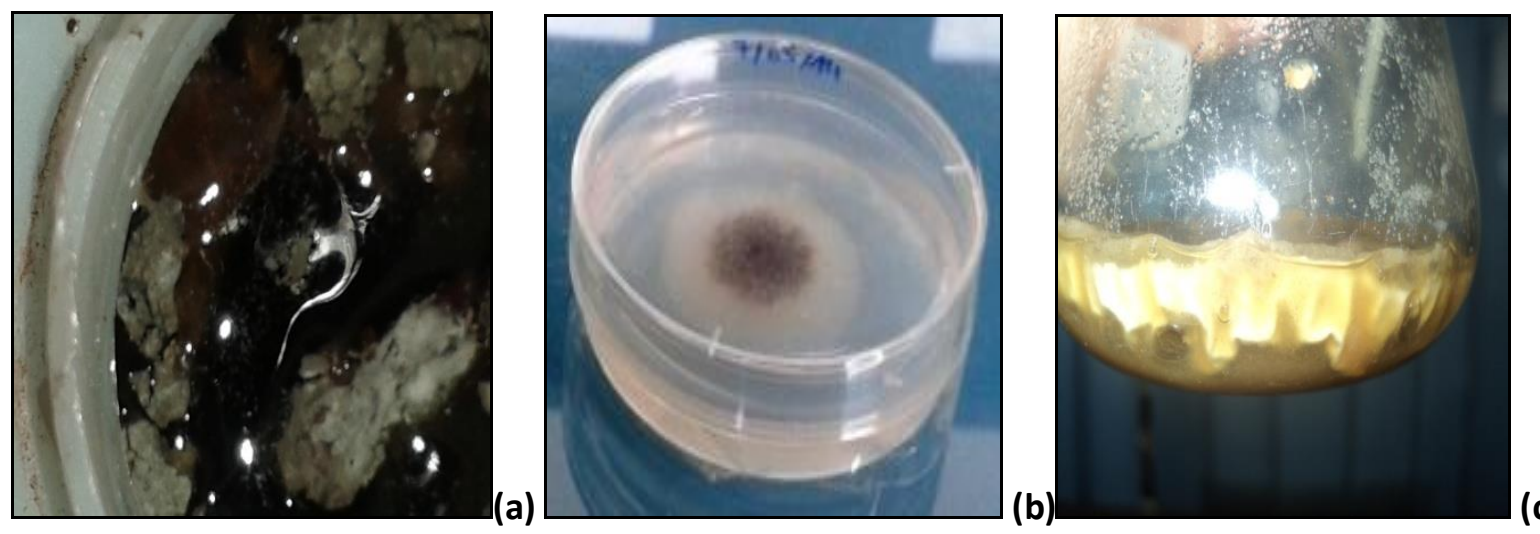

(c)

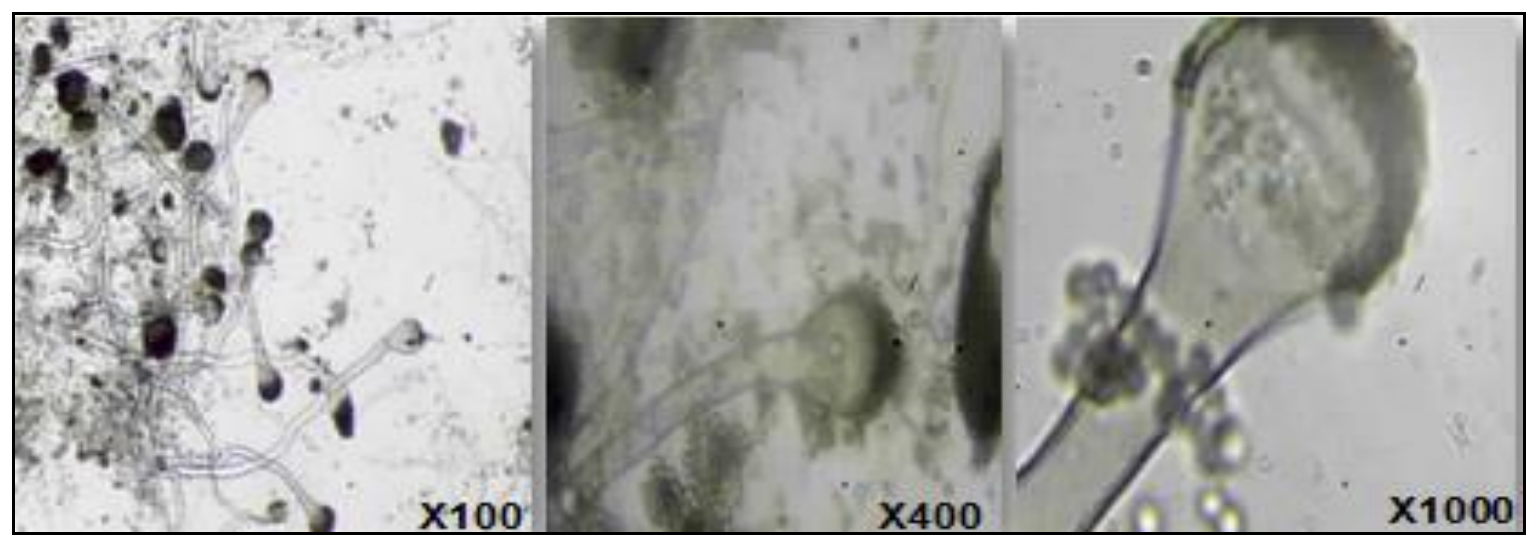

Figure 1. Morphological characteristics of the Chechia Mix cleaner fungal strain: (a) spontaneous growth on Chechia Mix, (b) cultivated in PDA, (c) cultivated in PDB and (d) through optical microscopic observations at 10,40 and 100 magnifications, after 3 days at $\mathrm{T}=30^{\circ} \mathrm{C}$

\section{Identification of the fungal strain and phylogenetic analysis}

The isolated fungus has grown spontaneously on Chechia wastewater and has presented visually an interesting potential on dye removal (Figure 1.a). The strain cultured at $30{ }^{\circ} \mathrm{C}$ in PDA for 3 days showed colonies with the following phenotypic characteristics: circular, curved, hairy, white at the 
circumference and black going to the middle with a colony diameter of 25-45 $\mathrm{mm}$ (Figure 1.b). When incubated in PDB, the fungus had a better white mycelium growth (Figure 1.c). The optical microscopy permitted the description of the appearance and the shape of mycelium and spores at different magnifications (Figure 1.d).

According colony morphology, conidial size and ornamentation, the strain can be assigned to Aspergillus section Nigri ${ }^{22}$. Figure 1.d showed that the mycelium has branched filaments with vesicles 45-80 $\mu \mathrm{m}$ wide, nearly globose. Phialides are flaskshaped terminated by spores or conidia which are very small in size $3.5-5 \mu \mathrm{m}$, not chinulate, very volatile and giving its color to the colonies. There were no sclerotia observed in the culture. The studied fungal strain exhibited the growth and the morphological characteristics of Aspergillus niger. Black aspergilli were isolated from various sources but the main one remains soil ${ }^{23}$. However, Samson et al. underlined that morphological structures can be helpful but the growth pattern was not sufficient to distinguish species including the species related to $A$. niger in particular ${ }^{22}$. Indeed, Black aspergilli are difficult to be recognized based only on their phenotypic characters. Frisvad et al. exposed some interesting methods that can be used in the diagnostics of the known and accepted species ${ }^{24}$. To identify the fungus cleaning Chechia Mix, the genomic fungal DNA (Figure 2.a) was amplified by PCR (Figure 2.b) which was realized using the universal primers ITS1 and ITS4. Those primers encompass the nuclear gene for the 5.8S rRNA and the flanking transcribed spacers ITS1 and ITS4 approximately $600 \mathrm{pb}$. The ITS nucleotide sequence of the amplified DNA was determined and analyzed with the NCBI database using the BLAST program. The nucleotide sequence showed 100\% homology with ITS of Aspergillus niger strain (Figure 2.c). The sequences that showed the highest similarity with the query sequence were found to belong to Ascomycetus fungi. The multiple alignment and phylogenetic tree (Figure 2.c) showed that the strain is Aspergillus niger. But ITS can only be used for the uni- and biseriate species classification while only four groups of A. niger related taxa can be identified ${ }^{22}$. Samson et al. highlighted that almost all species in Aspergillus section Nigri can be distinguished from each other using calmodulin and $\beta$-tubulin sequence data ${ }^{22}$. More analytic investigations could be carried out to specify the identification of the cleaning fungus following Abarca et al. ${ }^{23}$.
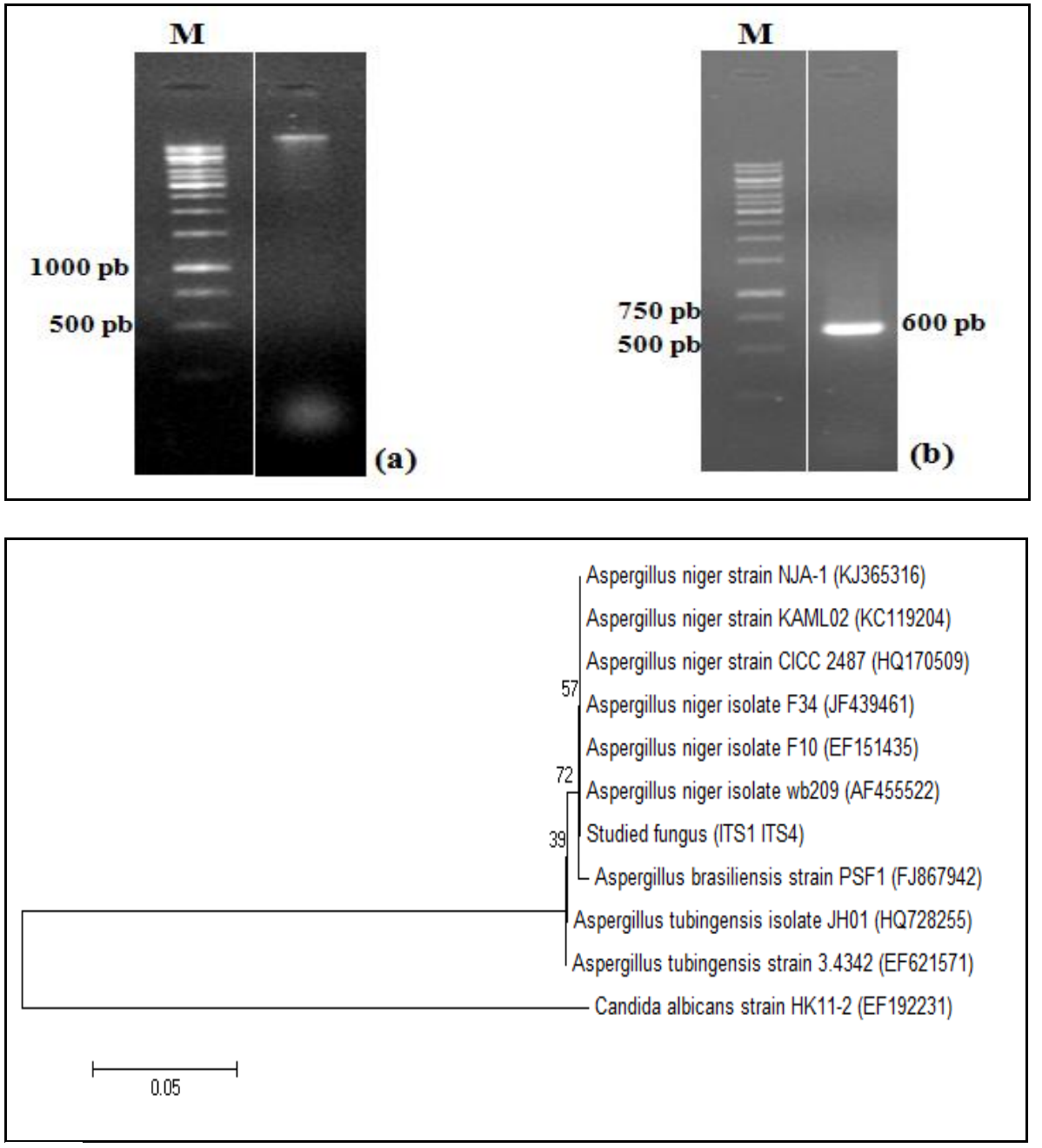

Figure 2.

Electrophoretic analysis of genomic DNA on (a) Agarose gel $0.8 \%$ and (b) Polymerase Chain Reaction products on Agarose gel 1\% M: Molecular Weight Marker. (c) Phylogenetic analysis based on ITS sequences of some Aspergilli strains, using the neighborjoining method on MEGA6.

(c) 


\section{Biological Treatment}

Chechia Mix biodegradation

Despite its specific pollutant, Chechia Mix could be successfully treated using a biological process with selected micro-organisms. That was prognosticated after Chechia Mix characterization with a $\mathrm{COD} / \mathrm{BOD}_{5}$ ratio of 2.16 and then demonstrated through the preliminary batch culture results depicted in Figure 3.

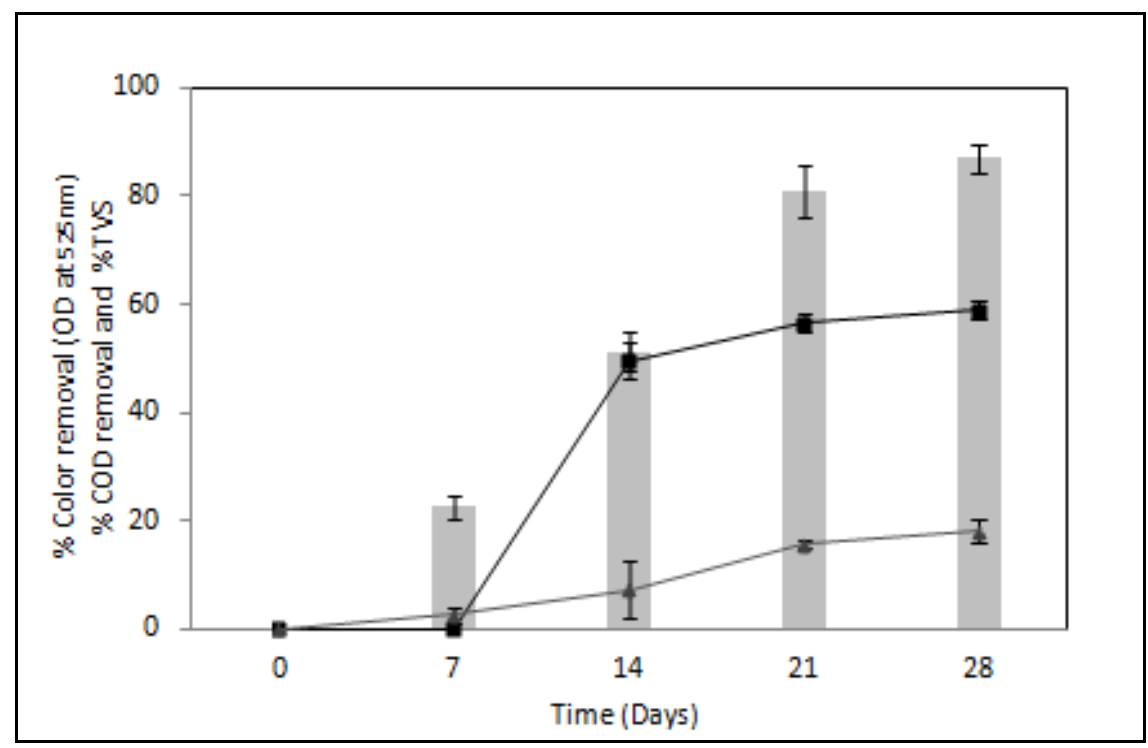

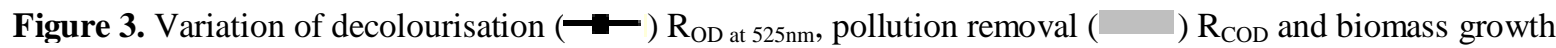
$(-) \mathrm{R}_{\mathrm{TVs}}$ yields during diluted Chechia Mix biotreatment by isolated Aspergillus niger inoculated at $10 \%$, under static conditions

Indeed, diluted Chechia Mix (25\%) treatment using the isolated Aspergillus niger (inoculum size $10 \%$ ) in static conditions presented increasing pollution and color removal. An interesting decolourisation yield of $59.06 \pm 1.51 \%$ and a large depollution performance illustrated by a COD removal yield of $87.05 \pm 2.68 \%$ was registered at the end of the treatment. In parallel, fungal biomass growth expressed in TVS yield increased progressively and achieved $18.16 \pm 1.94 \%$ at the end of the experience. Unlike in agrifood fermentation processes applications, a reduced biomass growth could be appreciated on the environmental field. Also, Aspergillus niger growth seemed to be strongly associated with enzymatic activities production as an increase of $\mathrm{pH}$ from $4.78 \pm 0.18$ to $8.73 \pm 0.12$ was noticed between the beginning and the end of treatments. Indeed, Fu and Viraraghavan explained that biomass cells produce enzymes such as laccase, manganese peroxidase and lignin peroxidase to mineralize the dyes ${ }^{25}$.

\section{Factors Effects}

Several authors have studied the degradation of textile wastewaters through the statistical design of experiments to optimize the treatment ${ }^{10}$. Even though, most of these studies were based on synthetic industrial effluents, the goal of the present work was to determine optimal conditions for the biodegradation of a real artisanal wastewater, the Chechia Mix. According to literature, several factors such as $\mathrm{pH}$, agitation, effluent dilution, inoculum size and substrate concentration affected the fading rate while salts and other nutrients had little effect on color removal. After the preliminary batch results demonstrating the biodegradation efficiency of Aspergillus niger, the Chechia Mix biotreatment conditions were optimized through full factorial experimental design repeated twice. Three factors were explored and chosen as independent quantitative variables, namely: inoculum size, Mix dilution and agitation. The monitoring of eight different batch systems generating two responses, decolourisation and pollution removal, was described in Table 2. In order to determine whether the observed differences between responses were significantly different, statistical analyses were carried by means of NemrodW® software. Differences between factors effects $(P)$ were compared with 0.05 . The NemrodW® software analysis of the data indicated that all factors effects were statistically significant $(P<0.05)$. 
Table 2. Biodegradation of Chechia Mix with Aspergillus niger by full factorial experimental design $2^{3}$ Responses Matrix of eight experiments (E1 to E8) with High (+1) and Low (-1) coded levels Factors (F1 to F3) and Regression coefficients $\left(b_{0}, b_{1} b_{2}\right.$ and $\left.b_{3}\right)$ calculated for color removal (Y1) and pollution removal (Y2)

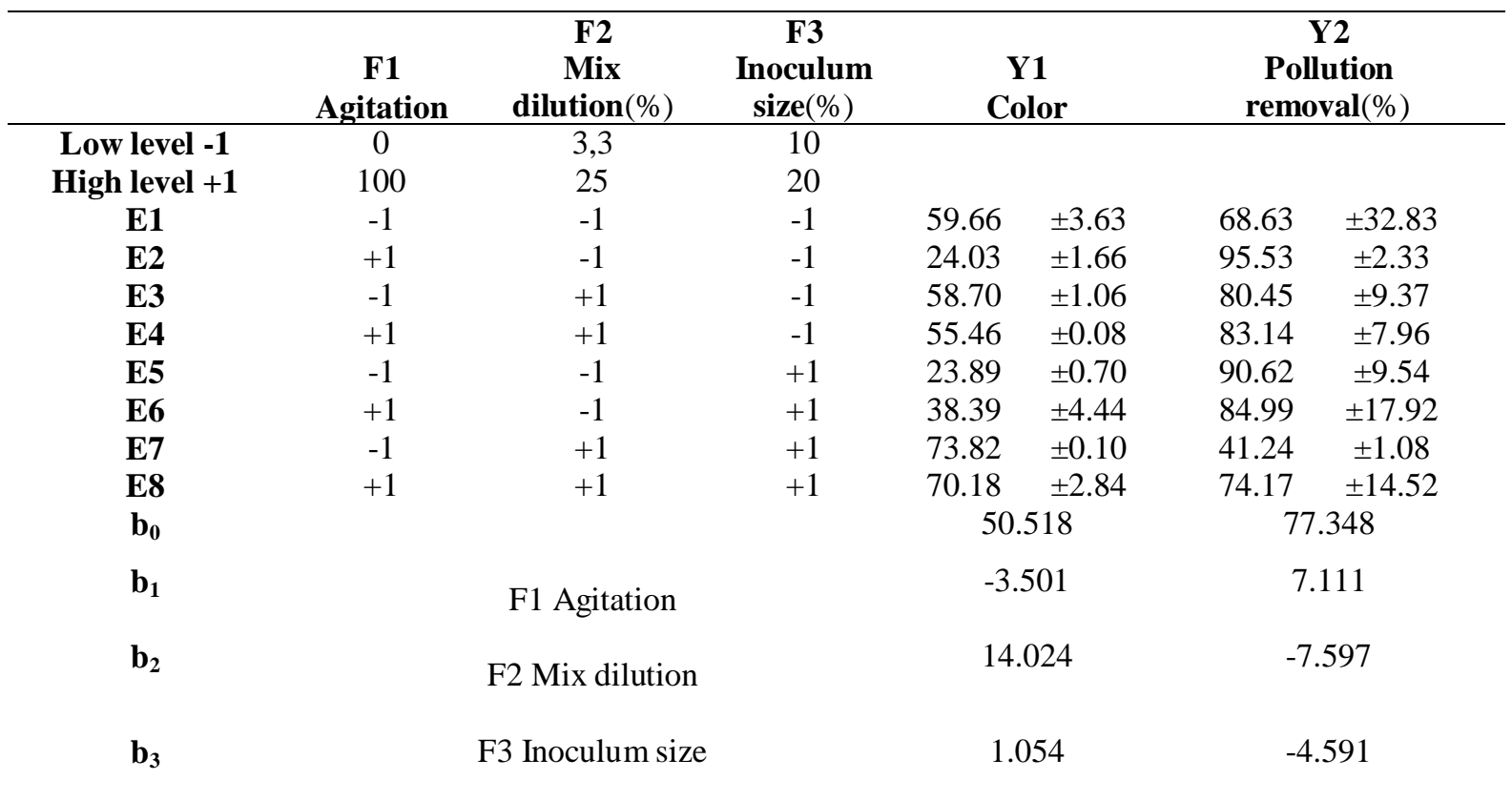

The statistical $\mathrm{p}$ values are calculated from analyses between different cultures $(\mathrm{p}<0.05)$.

According to the Table 2, the E7 system had remarkable performances with $73.82 \pm 0.10 \%$ of decolourisation and $40.5 \pm 1.08 \%$ of COD reduction. Also, the E2 system achieved $95.53 \pm 2.33 \%$ of pollution removal while it registered only $24.03 \pm 1.66 \%$ of color removal. The best performances were registered for the E8 system with a decolourisation of $70.18 \pm 2.84 \%$ and a COD removal of $74.17 \pm 14.52 \%$. There was no decolourisation in any of the uninoculated controls confirming the absence of intrinsic autoxidation phenomenon on the Chechia Mix. Thus, the best conditions for the Chechia Mix biotreatment corresponded to the initial conditions of the batch E8: $20 \%$ of inoculum size, $25 \%$ of Mix dilution and an agitation of $100 \mathrm{rpm}$. Ali et al. ${ }^{12}$ achieved more than $95 \%$ of decolourisation efficiency within $48 \mathrm{~h}$ for azo reactive dyes using Aspergillus foetidus, but digging into the mechanisms involved, no significant biotransformation in dye was noticed and the entire color removal was found to be due to bioadsorption .Similarly, divalent dyes like Acid Orange II and Acid Red 114 showed a great affinity to the fungal biomass cell wall of Myrothecium verrucaria and Aspergillus niger ${ }^{12}$. The fungal decolourisation mechanism involves the adsorption and/or enzymatic degradation ${ }^{7}$. Robinson et al. indicated that the textile effluent is not the adequate environment for the growth and preservation of fungal biomass, but fungi have a high capacity for accumulation of heavy metals and dyes in addition to ligninolytic enzymes secretion that has a strong oxidizing power ${ }^{4}$. Unlike bacteria like Bacillus subtilis, Bacillus cereus, Pseudomonas.sp, Klebsiella pneumonia, Acinetobacter liquefaciens and Aeromonas hydrophila where the degradation of the dyes is intracellular, degradation by fungus is extracellular ${ }^{26}$. As related by Shyamala Gowri et al., the decolourisation could be a secondary metabolic activity linked to the fungus ligninolytic degradation activity ${ }^{27}$.

Statistical analysis and selection of the optimal conditions

NemrodW® software provided considerable useful information and reaffirmed the utility of statistical analysis for experiments conduct in order to be decisive when it came to the selection of the optimal conditions for Chechia Mix biotreatment. In order to evaluate the effect of each factor on the studied responses, weighting coefficients were generated by NemrodW® software and summarized in Table 2. The regression coefficient $b_{1}$ was positive for $\mathrm{Y} 2$ and negative for $\mathrm{Y} 1$ which indicated that agitation had a positive effect on pollution removal at its high level while its effect is positive at its low level for color removal. On the contrary, the study of the regression coefficients $b_{2}$ and $b_{3}$ revealed that Mix dilution and inoculum size had positive effects at their high levels for color removal and at their low levels for pollution removal. To summarize, the best conditions for pollution removal were agitation at $100 \mathrm{rpm}$, mix effluent dilution at 3.3\% and biomass inoculation at $10 \%$, whereas the optimal operating conditions for color removal were Mix dilution at $25 \%$ and $20 \%$ as inoculum size without agitation. As the major and specific pollutant of this wastewater was an azo dye, the most important biotreatment target of this study remained the color removal. Thus, selected optimal conditions for Chechia Mix 
biotreatment were defined as follows: agitation at $100 \mathrm{rpm}, 25 \%$ of mix dilution and $20 \%$ of inoculum size. Due to the weight coefficients presented in Table 2, mathematical models were also established. The experiences can be described through the following mathematical models in which the factors F1, F2 and F3 were respectively agitation, Mix dilution and the inoculum size; and the responses $\mathrm{Y} 1$ and Y2 were respectively the color and pollution removals yields:

\section{$\mathrm{Y} 1=\mathbf{R}_{\mathrm{OD} 525}=\mathbf{5 0 . 5 1 8}-\mathbf{3 . 5 0 1}$ Agitation $+\mathbf{1 4 . 0 2 4}$ Mix dilution +1.054Inoculum Size}

$\mathrm{Y} 2=\mathbf{R}_{\mathrm{COD}}=77.348+7.111$ Agitation $-7.597 \mathrm{Mix}$ dilution - 4.591Inoculum Size

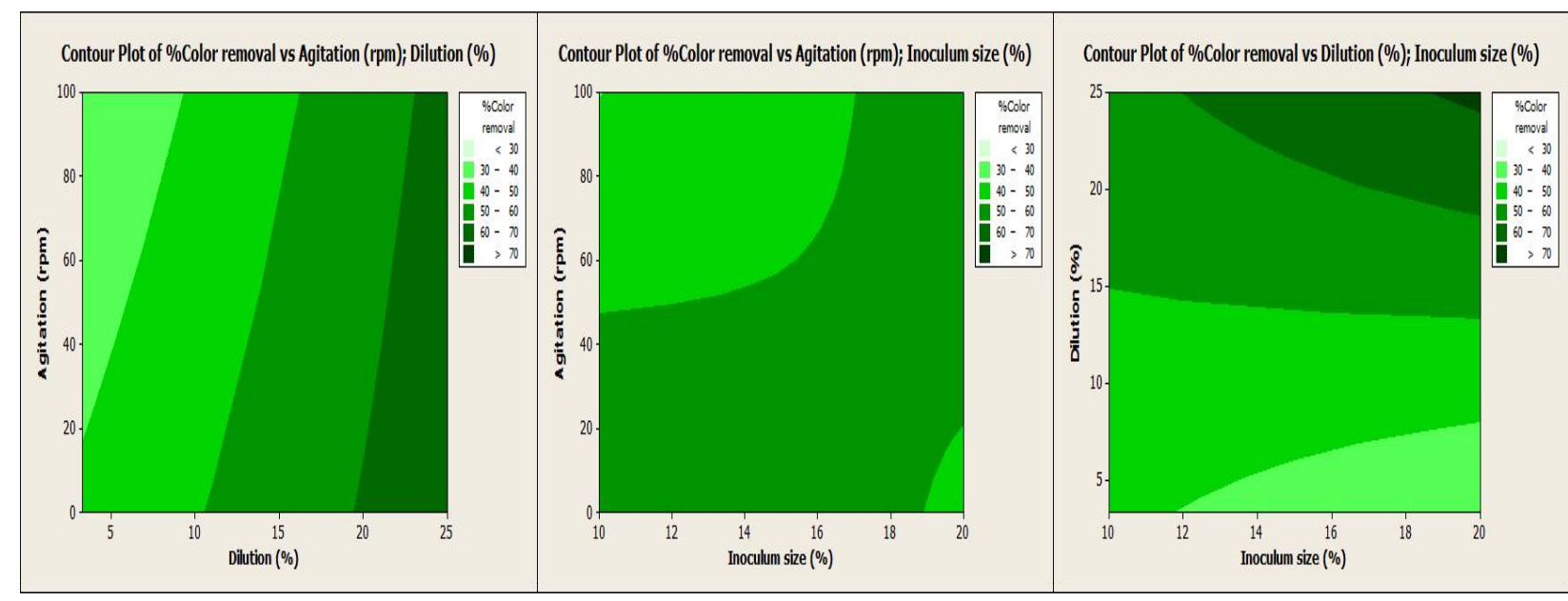

(a)

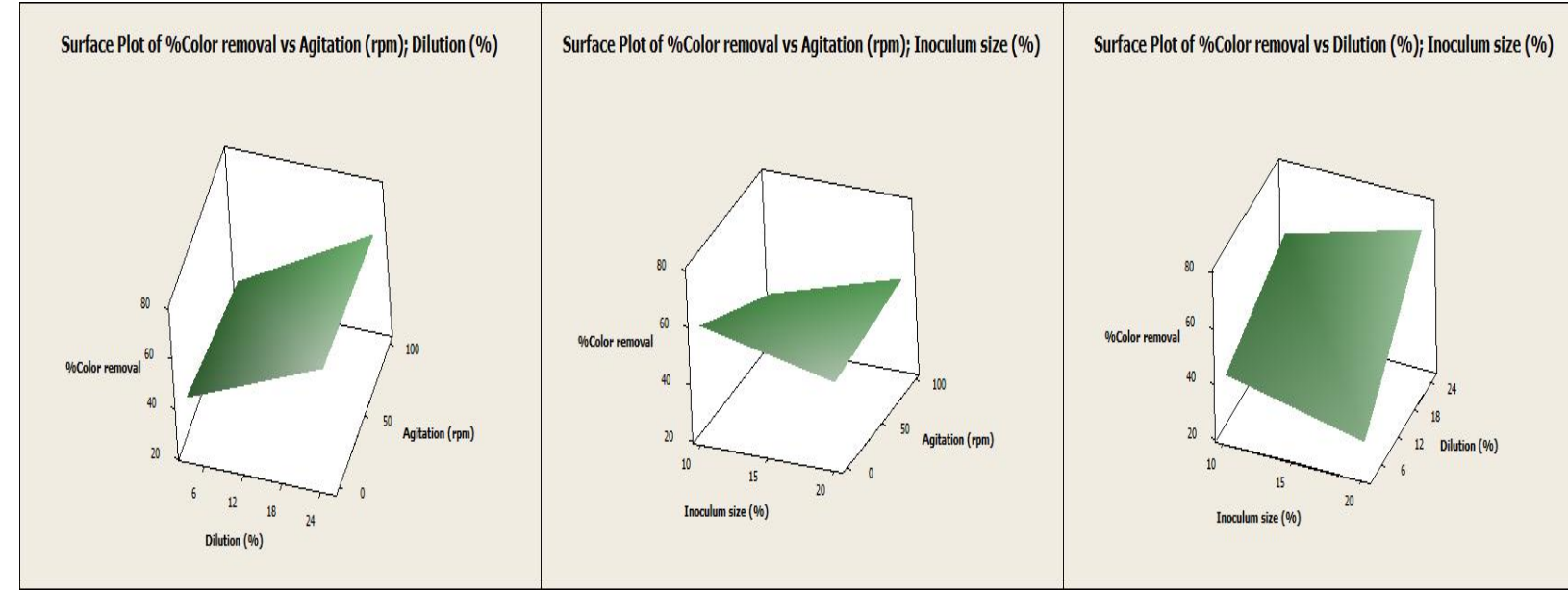

(b)

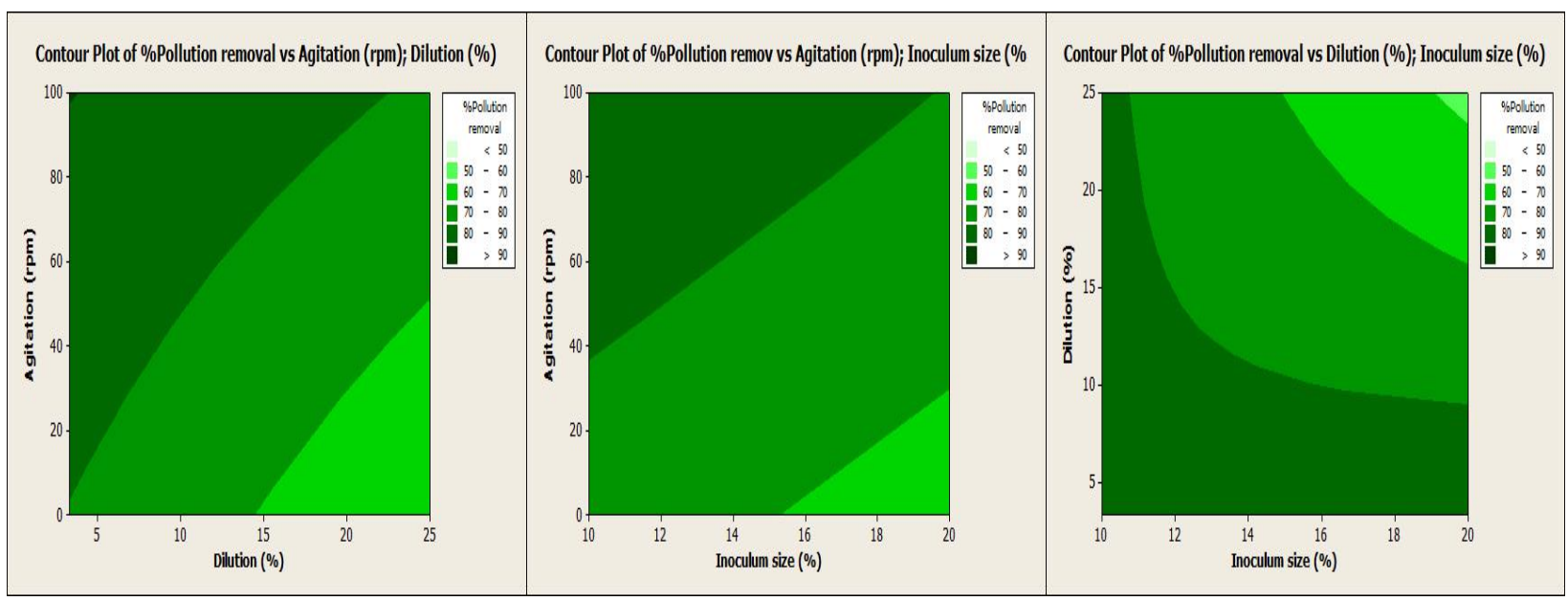

Figure 4. Contour and surface plots ( $\mathrm{a}$ and $\mathrm{b}$ ) showing interactions between agitation, Mix dilution and inoculum size on the color removal response. Contour plots (c) presenting interactions between agitation, Mix dilution and inoculum size on the pollution removal response 
To investigate the interaction between different factors and visualize how the studied factors affected color and pollution removal after 35 days of experiment, a graphical representation of contour plots was generated using Minitab (Figure 4). The shapes of the contour plots indicated the nature and extent of the interactions. Contour plots of color removal showed in Figure 4.a underlined that color removal was in a range of $40-50 \%$ when inoculum size was around $20 \%$ combined to agitation at a range of $0-20 \mathrm{rpm}$. Color removal efficiency increased at a range of $60-70 \%$ if agitation at 50-100 rpm was combined to inoculum size between 16$20 \%$. Moreover, color removal exceeded $70 \%$ when Mix dilution of $20-25 \%$ is combined to agitation of $0-100 \mathrm{rpm}$ or when inoculum size ranged from $15-20$ $\%$ was combined to Mix dilution 24-25\%. Surface Plots of color removal illustrated in Figure 4.b confirmed that high decolourisation rates were strongly correlated with the high level of inoculum size and Mix dilution. The increase of Mix dilution improved decolourisation while high level of agitation could give a positive effect. Agitation enhanced oxygen availability but Ikehata et al. explained also that $\mathrm{LiP}$ and $\mathrm{MnP}$ production by $P$. chrysosporium could be suppressed because of agitation on submerged culture ${ }^{28}$. On another side, the decrease in COD on Chechia Mix led to an increase in the pollution removal rate. Contour plots of pollution removal in Figure 4.c indicated that the pollution removal rate was between 70 and $80 \%$ when Mix dilution was around $25 \%$, inoculum size $15-20 \%$ and agitation ranged $50-100 \mathrm{rpm}$. Hence, to maximize pollution removal, the variables must be kept at the lowest tested levels for Mix dilution and inoculation size, but kept at the highest ones for agitation. Regarding the effects of the different factors, Mix dilution and then inoculum size were the largest influencing factors on the color removal, while concerning agitation it was more important to achieve the best pollution removal rate rather than to attend the best decolourisation performance. To summarize, Mix dilution of $25 \%$, inoculum size of $20 \%$ and agitation at $100 \mathrm{rpm}$ seemed to be the optimal conditions for Chechia Mix biotreatment by Aspergillus niger. With no special high energy consumer operating conditions, biotreatment by Aspergillus niger seemed to be a viable eco-friendly and low cost process way to remove colors from Chechia wastewaters.

Similar results have been found by Kim and Shoda ${ }^{29}$ on molasses decolourisation and Asses et al. ${ }^{19}$ on olive mill wastewater decolourisation by Geotrichum candidum. When studying the interaction between $\mathrm{pH}$ and agitation speed for the decolourisation and enzyme synthesis, Asses et al. showed that the utmost of decolourisation was obtained with low tested levels ${ }^{19}$. According to Manai et al ${ }^{21}$, the filamentous fungus Chaetomium globosum seemed to have a great capacity for dye removal via the biodegradation mechanism. Thus, it should be necessary to investigate, deeply, the relation between decolourisation and extracellular enzyme activities from the isolated Aspergillus niger. The biological action of the isolated Aspergillus niger on Chechia dyes degradation and/or transformation could be further evaluated by FT-IR spectra analysis of the post biotreated Chechia effluent at optimal conditions.

\section{FT-IR analysis of Chechia effluents}

Infrared spectroscopy is largely employed for qualitative materials characterization. Indeed, the signals obtained from FT-IR are caused by substance-specific vibration modes of the molecules and can be attributed to functional group ${ }^{21}$. Infra red spectra of Chechia Mix confirmed the theoretical major presence of the Acid Red 27 dye as Infra red spectrum of the Chechia Mix before treatment (Figure 5.a) complies completely with the pure dye one (Figure 5.b).

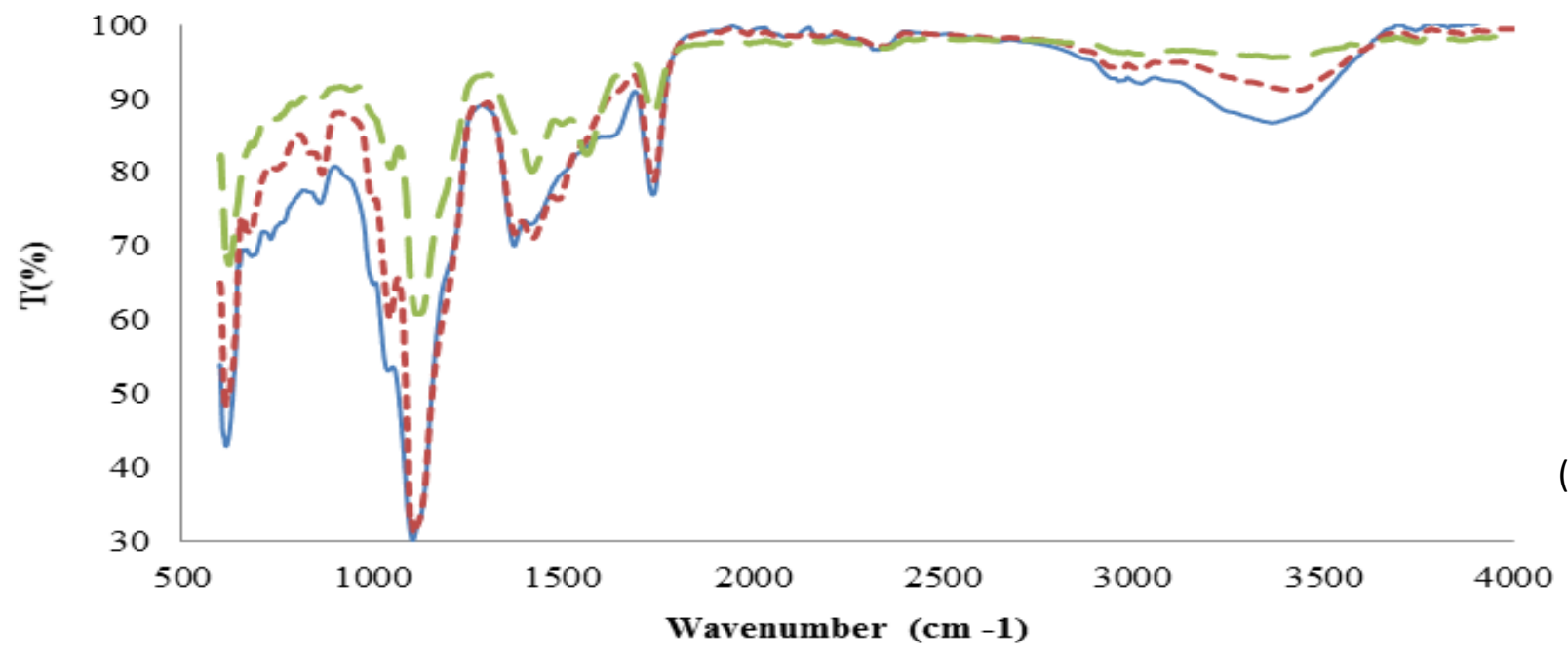

(a) 


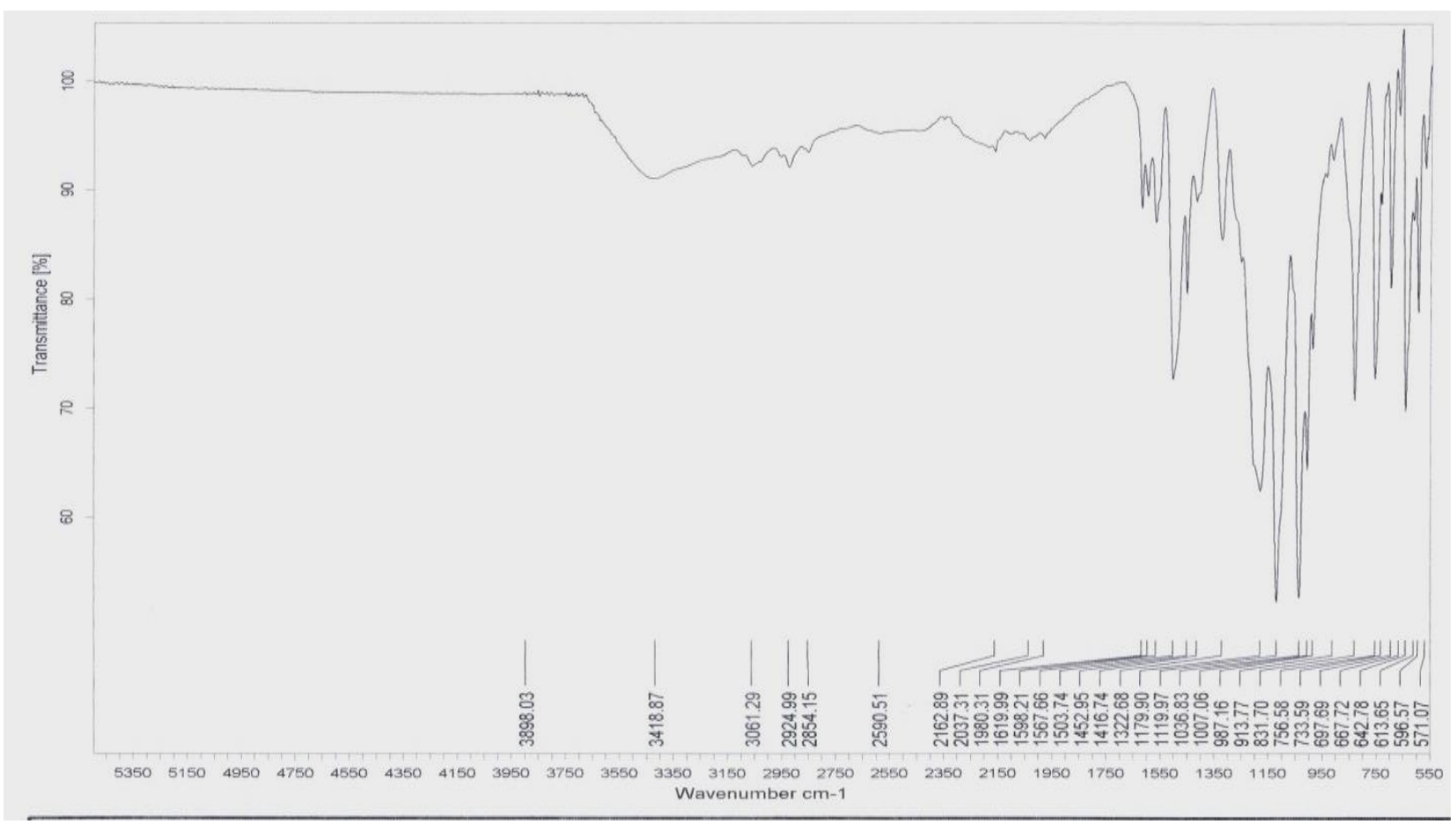

Figure 5. FT-IR spectra of Chechia effluents before and after biotreatment (a) under optimized conditions: $20 \%$ Inoculum size, $\mathrm{T}=30^{\circ} \mathrm{C}$ and Agitation $=100 \mathrm{rpm}\left(--\right.$ untreated Mix, ${ }^{---\cdot}$ diluted Mix $(25 \%)$ before treatment, - diluted Mix (25\%) after treatment). (b) Infra-red spectra of the major Dye Acid Red 27

$$
\mathrm{C}_{20} \mathrm{H}_{11} \mathrm{~N}_{2} \mathrm{Na}_{3} \mathrm{O}_{10} \mathrm{~S}_{3}
$$

The right section $\left(<1500 \mathrm{~cm}^{-1}\right)$ of an infrared spectrum refers to its "fingerprint", the large number of bands and their nature revealed several structural pieces of information. All the bands in this right section of both spectra (Figure 5.a and b) were found in the same positions and relative intensities confirming that Acid Red 27 dye was the major dye of the Chechia Mix. The left section (> $\left.1500 \mathrm{~cm}^{-1}\right)$ included most of the characteristic bands of functional groups. The $\mathrm{CH}$ absorptions peaks around $3000 \mathrm{~cm}^{-1}$ illustrated the organic nature of Chechia Mix effluent. Infrared analysis based on Coates (2000) revealed bands $v \mathrm{C}=\mathrm{O}\left(1700 \mathrm{~cm}^{-1}\right), \mathrm{ABC}$ by conjugation to $1600 \mathrm{~cm}^{-1}, v \mathrm{C}=\mathrm{N}\left(1650 \mathrm{~cm}^{-1}\right), v \mathrm{NH}$ $\left(3300 \mathrm{~cm}^{-1}\right)$ and $v \mathrm{CH}\left(3000-3100 \mathrm{~cm}^{-1}\right)$. FT-IR spectra of treated and untreated Chechia Mix shown in Figure 5.a. permitted further qualitative investigations on the effect of the best treatment conditions batch bioreactor E8. The FT-IR spectra of untreated dyes showed the specific peaks in the fingerprint region (1500-500 $\mathrm{cm}^{-1}$ ) for the monosubstitued and para-disubstituted benzene rings ${ }^{30}$. The peak around $1640 \mathrm{~cm}^{-1}$ stands for the $\mathrm{C}=\mathrm{C}$ stretching of the benzene ring. The observed peaks in the region $\left(3200-3500 \mathrm{~cm}^{-1}\right)$ are assigned to the $\mathrm{O}-\mathrm{H}$ stretching. The dye effluent presented a characteristic peak in the range $1350-1000 \mathrm{~cm}^{-1}$ related to the $\mathrm{S}=\mathrm{O}$ stretch band with a first significant absorbance peak at $1100 \mathrm{~cm}^{-1}$ and a second for the C-S stretching vibrations due to sulphur compound bonded to the activated carbons. Comparison of FTIR spectra of Chechia effluent dye after decolourisation clearly indicated the biodegradation of the initial dye compound by Aspergillus niger. It can be seen that the bands located within the range $1610 \mathrm{~cm}^{-1}-1630 \mathrm{~cm}^{-1}$ and at $1500 \mathrm{~cm}^{-1}$ were due to azo linkages $-\mathrm{N}=\mathrm{N}-$ on aromatic structures and $-\mathrm{N}=\mathrm{N}$ - stretching on Acid Red 27. The bands at $1710 \mathrm{~cm}^{-1}$ are assigned to the $\mathrm{C}=\mathrm{O}$ stretching of Acid Red. The characteristic band at $1640 \mathrm{~cm}^{-1}$ of $\mathrm{C}=\mathrm{C}$ of the benzene ring persisted even after the increase of the exposure time with the fungus. However, the bands assigned to aromatic skeletal vibrations have been reduced after biological treatment confirming the degradation of the dyes. The analysis of the spectral characteristics of treated effluent revealed a peak at $1261 \mathrm{~cm}^{-1}$ for $-\mathrm{C}-\mathrm{N}$ stretch with supporting peak at $1098 \mathrm{~cm}^{-1}$ which might be attributed to the formation of primary and secondary amines ${ }^{30}$. The fact that no new peaks appeared between $3300 \mathrm{~cm}^{-1}$ and $3500 \mathrm{~cm}^{-1}$ attributed to azo bonds and $\mathrm{OH}$ groups in $\alpha$ position relative to the azo linkage and in the region between $1340 \mathrm{~cm}^{-1}$ and $1250 \mathrm{~cm}^{-1}\left(-\mathrm{NH}_{2}\right)$ after the treatment suggested that the azo linkage could be converted into $\mathrm{NH}_{3}$ or $\mathrm{N}_{2}{ }^{31}$. Moreover, the presence of new peaks at $850 \mathrm{~cm}^{-1}$ and $950 \mathrm{~cm}^{-1}$ and the peak at 1140 $\mathrm{cm}^{-1}$ that could belong to acetate, formats, propionates, benzoates, etc. suggested that the products were subjected to irreversible chemical changes, probably due to concomitant biodegradation and autoxidation reactions of the products formed during the reductive dye degradation ${ }^{31}$. In addition, the persistence of the sulphur groups of sulphonated dyes even after treatment reflects their general stability. These 
results suggested the ability of Aspergillus niger in the biodegradation of xenobiotics and recalcitrant compounds such as Chechia effluent dyes, characterized by a non-specific action on aromatic groups.

\section{Conclusion}

Chechia Mix effluent was first time characterized as highly polluted especially because of its specific dark red color linked to its major pollutant the Acid Red 27 dye. An interesting Chechia dye removing Aspergillus niger, isolated from the wastewater ecosystem, having a potential application bioremediation of artisanal and industrial dye-rich textile effluents, was cultured and characterized. A full factorial experimental design $2^{3}$ confirmed the Chechia Mix biotreatment efficiency using the selected fungal strain and revealed its optimal conditions: agitation at $100 \mathrm{rpm}$, Mix dilution of $25 \%$ and inoculum size of $20 \%$. The optimized biotreatment assays reached $70.18 \pm 2.84 \%$ in terms of color removal, and $74.17 \pm 14.52 \%$ of COD reduction. Decolourisation by biodegradation of the major dye Acid Red 27 was first time bioremediation of Chechia wastewater as an ecofriendly and low cost method to solve a national environmental issue.

\section{Acknowledgements}

The present research study was supported by the Ministry of Higher Education and Scientific Research - Tunisia under research Program of Laboratory of Ecology and Microbial Technology LETMi. The authors thank particularly the private Chechia dyeing plant Ben Aaba for providing Chechia effluent samples and all Chechia artisans for their cooperation and support in field investigation and experimental work.

\section{References}

1- A. B. dos Santos, F. J. Cervantes, J. B. Van Lier, Bioresour Technol., 2007, 98, 2369-2385.

2- A. Alinsafi, F. Evenou, E. Adbulkarim, M. Pons, O. Benhammou, A. Yaacoubi, Dye Pig., 2007, 4, 439-445.

3- B. Lodha, S. Chaudhari, J. Hazard. Mater., 2007, 148, 459-66.

4- M. Solís, A. Solís, H. I. Pérez, N. Manjarrez, M. Flores, Process Biochem., 2012, 47,17231748.

5- V. K.. Gupta, Suhas, J. Env. Manag., 2009, 90, 2313-2342.

6- S. Erum, S. Ahmed, African J. Biotechnol., 2011, 10, 3399-3411.

7- M. Sudha, A. Saranya, G. Selvakumar, N. Sivakumar, Int. J. Curr. Microbiol. App. Sci. 2014, 3, 670-690.
8- Y. Fu, T. Viraraghavan, Water Qual. Res. J. Canada, 2000, 35, 95-111.

9- P. Blanquez, N. Casas, X. Font., M. Gabarrell, M. Sarrá, G. Caminal, Water Res., 2004, 38, 2166-2172.

10- F. Ay, Cocay, E. Catalkaya, F. Kargi, J. Hazard. Mater., 2009, 162, 230-236.

11- G. M. B. Soares, M. T. Pessoa Amorim, R. Hrdina, M. Costa-Ferreira, Process Biochem., 2002, 37, 581-587.

12- N. Ali, Ikramullah, G. Lutfullah, A. Hameed, S. Ahmed, World. J. Microbiol., 2008, 24, 10991105.

13- C. L. R. Jaidev, G. Narasimha, Asian J. Micro., Biotech. Env. Sci., 2010, 12, 353-357.

14- S. A. Omar, J. Env. Sci. Tech., 2016, 9, 149-156.

15- N. Saitou, M. Nei, Mol. Biol. Evol., 1987, 4, 406-425.

16- K. Tamura, G. Stecher, D. Peterson, A. Filipski, S. Kumar, Mol. Biol. Evol., 2013,30, 27252729.

17- J. Wang, K. Li, C. Yang, Y. Wang, J. Jia, Electrochem. Commun., 2012, 18, 51-54.

18- J. Goupy, Anal. Chim. Acta., 2005, 544,184190.

19- N. Asses, L. Ayed, H. Bouallagui, I. Ben Rejeb, M. Gargouri, M. Hamdi, Bior. Technol., 2009,100, 2182-2188.

20- R. Khlifi, L. Belbahri, S. Woodward, M. Ellouz, A. Dhouib, S. Sayadi, T. Mechichi, J. Hazard. Mater., 2011,175, 802-808.

21- I. Manai, B. Miladi, A. El Mselmi, I. Smaali, A. Ben Hassen, M. Hamdi, H. Bouallagui, J. Environ. Manage., 2016,170, 8-14.

22- R. A. Samson, P. Noonim, M. Meijer, J. Houbraken, JC. Frisvad, J. Varga, Stud. Mycol., 2007, 59, 129-145.

23- M. L. Abarca, F. Accensi, J. Cano, F. J. Cabañes, Antonie Van Leeuwenhoek, 2004, 86, 33-49.

24- J. C. Frisvad, T. O. Larsen, R. Vries, M. Meijer, J. Houbraken, F. J. Cabañes, K. Ehrlich, R. A. Samson, Stud. Mycol., 2007, 59, 31-37.

25- Y. Fu, T. Viraraghavan, Bioresour. Technol., 2001,793, 251-262.

26- E. Khelifi, H. Bouallagui, Y. Touhami, J. Godon, M. Hamdi, Desalin.Water Treat., 2009, 2, 310-316.

27- R. Shyamala Gowri, R. Vijayaraghavan, P. Meenambigai, Int. J. Curr. Microbiol. App. Sci., 2014, 3 ,

$$
\text { 421-436. }
$$

28- K. Ikehata, I. D. Buchanan, D. W. Smith, J. Environ. Eng. Sci., 2004, 3, 1-19.

29- J. Kim, M. Shoda, Appl. Environ. Microbiol., 1999. 65, 1029-1035.

30- J. P. Coates, P. H. Shelley, Encyclopedia of Analytical Chemistry, Ed. R.A. Meyers. J. Wiley \& Sons, Ltd., Chichester, UK, 2000, 8217-8240.

31- E. Franciscon, A. Zille, F. Dias Guimaro, Inter. Biodet. Biodeg. , 2009, 63,280-288. 